\title{
Efeitos dos setores econômicos e da escolaridade sobre o rendimento do trabalho no Rio Grande do Sul*
}

Valter José Stülp**

Resumo: O artigo analisa os efeitos dos setores da atividade econômica e da escolaridade dos trabalhadores sobre a sua probabilidade de auferirem maiores rendimentos do trabalho, ao nível dos municípios do Rio Grande do Sul. Como o setor agrícola deste estado emprega 20\% do total da mão de obra ocupada, especial ênfase é dada ao mesmo.

A base de dados é o Censo Demográfico de 2000 do IBGE.

A análise estatística dos dados é realizada através do modelo Logit.

Verificou-se que são limitadas as possibilidades de o setor agrícola, enquanto gerador do produto primário, aumentar a probabilidade dos trabalhadores de um município de auferirem maiores rendimentos do trabalho. Para maiores rendimentos é indispensável que o município agregue outros setores como, por exemplo, os que são responsáveis pela industrialização, armazenagem e transporte do produto. Aliada à esta agregação de setores, a qualificação do trabalhador para poder assumir as novas funções é importante, contribuindo para maiores rendimentos do trabalho.

Palavras-chave: rendimento do trabalho, agropecuária, escolaridade do trabalhador.

*Este artigo contou com a colaboração do CNPq na concessão de uma bolsa de iniciação científica. O autor agradece a colaboração do bolsista Stephan Sawitzki.

**PhD em Economia Agrícola. Professor do Departamento de Ciências Econômicas - FACE -PUCRS.stulp@zaz.com.br 


\section{Classificação JEL: J31, Q18}

Abstract - The article analyzes the effects of economic sectors and educational level of workers on their probability to earn higher wages, at the county level in the state of Rio Grande do Sul. Special emphasis is given to the agricultural sector, since it employs $20 \%$ of the total labor force occupied in the state.

The IBGE Demographic Census of 2000 is the basis for the data.

Logit is the statistical model used for the analysis.

One of the conclusions of the analysis is that the possibility of the agricultural sector, in a county, to generate higher wages is limited, as long as it remains solely a producer of the primary product. In order to generate higher wages, it is necessary that the county aggregates other sectors, as for example, industrialization, storage and transportation. Besides, the qualification of the worker is also important, so he can assume new job opportunities in the aggregated sectors, which contributes for higher wages.

Key-words: labor income, agriculture, educational level.

Classification JEL: J31, Q18

\section{Introdução}

O crescimento econômico, como a simples variação quantitativa da renda, não define, por si só, o desenvolvimento econômico de um país. Este envolve mudanças qualitativas no modo de vida das pessoas, nas instituições e nas estruturas produtivas. Porém, o crescimento econômico contínuo que resulta na elevação da renda da população em ritmo superior ao crescimento demográfico e acompanhado de mudanças de estruturas e melhoria de indicadores econômicos e sociais per capita, definiria o desenvolvimento econômico (Souza, 1995).

Os maiores níveis de renda devem ser traduzidos não só em termos de renda per capita mais elevada, mas que signifiquem, também, mais renda para um maior número de pessoas. Isto possibilitará que maiores 
parcelas da população tenham acesso a uma melhor alimentação, moradia, serviços de saúde, mais educação, mais segurança, etc. que são as qualidades de um país desenvolvido.

Um dos elementos que influencia os níveis de renda da população de um país ou uma região é certamente o rendimento do trabalho auferido pelas pessoas ocupadas nos diferentes setores da atividade econômica. Dentre os setores da atividade econômica, a agricultura tem sido, tradicionalmente, aquele que apresenta os rendimentos do trabalho mais baixos. Isto explicaria em grande parte a migração rural-urbana.

Muitos dos trabalhadores rurais que migram para centros urbanos se dirigem, inicialmente, às cidades próximas aos seus locais de residência. Não encontrando oportunidades de emprego nestas sedes municipais eles se deslocam aos grandes centros urbanos, provocando um verdadeiro inchaço das cidades maiores que não apresentam condições de infra-estrutura para absorver toda esta população.

Ainda, com o avanço tecnológico nos outros setores que não o agrícola, as dificuldades para a mão de obra rural, não treinada, encontrar emprego nos mesmos, se tornam cada vez maiores.

É necessário que medidas sejam tomadas, ao nível dos municípios, visando, em primeiro lugar, reter o trabalhador rural no seu meio, propiciando-lhe a oportunidade de auferir maiores rendimentos pelo seu trabalho. Isto talvez pudesse ser realizado pela introdução de outros setores da atividade econômica, como a agroindústria, no meio rural. Em segundo lugar, é necessário que outros setores econômicos também sejam desenvolvidos, ao nível dos municípios, para que o trabalhador não migre para os grandes centros urbanos.

Uma pergunta que surge, portanto, é como os diferentes setores da atividade econômica influenciam os rendimentos do trabalho? A resposta a esta questão pode orientar a definição dos setores a serem desenvolvidos em municípios do Estado, quer seja no seu meio rural ou urbano.

Mas, além de gerar novas oportunidades de trabalho é necessário também qualificar o trabalhador para que possa assumir estas novas funções. Um dos requisitos para a qualificação, a qual possibilita maiores rendimentos do trabalho, é o nível de escolaridade.

Portanto, dois fatores parecem ser importantes para a elevação dos 
níveis de renda do trabalhador no município: a disponibilidade de opções de trabalho em setores que ofereçam remuneração mais elevada e a qualificação do trabalhador para assumir suas funções nestes postos de trabalho, para o que a escolaridade é essencial.

O conhecimento dos efeitos sobre o rendimento do trabalho dos diversos setores da atividade econômica é importante para a orientação de medidas de política econômica destinadas ao desenvolvimento daqueles que apresentam um maior impacto. Da mesma forma é necessário avaliar como os diferentes níveis de escolaridade podem interferir nos níveis de rendimento do trabalho, para orientar uma política educacional dirigida ao trabalhador.

O objetivo deste estudo é avaliar o efeito dos setores da atividade econômica e do nível de escolaridade dos trabalhadores sobre o rendimento do trabalho nos municípios do Rio Grande do Sul.

Espera-se que as conclusões possam orientar medidas de política econômica e educacional dirigidas aos trabalhadores dos municípios do Rio Grande do Sul, especialmente aos trabalhadores do meio rural, pois a agricultura deste estado ainda emprega $20 \%$ do total da mão de obra ocupada nos diversos setores da economia (IBGE, 2000).

\section{Revisão de Literatura}

Este item apresenta as conclusões de diversos autores sobre as diferenças entre os rendimentos do trabalho no meio rural e urbano e os efeitos da escolaridade sobre os mesmos.

Lewis (apud Souza, 1995, p.166) afirmava que, nas fases iniciais do desenvolvimento de um país, haveria na agricultura oferta ilimitada de mão de obra com produtividade marginal do trabalho tendendo a zero. Esta mão de obra migraria para o setor industrial, onde a produtividade seria maior, propiciando salários mais elevados. Somente em fases posteriores do desenvolvimento, quando a mão de obra se tornaria mais escassa na agricultura, haveria elevação dos salários neste setor.

No entanto, mais tarde, Lewis reformulou a sua abordagem, no sentido de que a agricultura não deve ter um papel passivo no processo de desenvolvimento. Deve haver programas de extensão rural, incentivos ao cooperativismo, a capacitação tecnológica do produtor rural, a for- 
mação de agroindústrias, financiamentos para irrigação, fornecimento de energia elétrica, etc. visando contribuir para fixar o homem no campo (Souza, 1995, p.170).

Johnston e Mellor (1961) já enfatizaram a necessidade do crescimento da renda do setor agrícola para o mesmo se constituir em um mercado para os produtos industriais e via capitalização poder gerar uma oferta crescente de alimentos. Assim, ao mesmo tempo em que a renda de outros setores cresce, a da agricultura também deveria aumentar.

Bacha (1979) analisando os fatores que explicam as diferenças de salários entre os setores urbano e rural, no Brasil, no período de 1940 a 1978, concluiu que estes foram: a estrutura agrária, a evolução das relações de troca desfavoráveis à agricultura, a política salarial do governo e a força dos sindicatos.

Estudos mais recentes verificaram que as diferenças entre os rendimentos do trabalho do setor urbano e rural persistem.

Waquil e Mattos (2002), utilizando dados da Pesquisa Nacional por Amostra de Domicílios (PNAD) do Instituto Brasileiro de Geografia e Estatística (IBGE) referentes ao período de 1981 a 1999, concluíram que a renda média auferida pela população rural do Rio Grande do Sul era consideravelmente inferior à renda média auferida pela população urbana do estado. A distribuição da renda, tanto na população rural quanto na urbana, era bastante assimétrica. Em 1999, 74\% das pessoas da população rural estavam abaixo do seu nível médio de renda que era de $R \$ 377,59$. Na população urbana $73 \%$ das pessoas se situavam abaixo do seu nível médio de renda de R\$664,20. Na década de 1990 teria havido uma tendência de redução da concentração de renda no espaço urbano, porém de estabilidade no meio rural.

Corrêa et al. (2002) afirmam que, de 1995 a 1999, reduziu-se a desigualdade entre as pessoas ocupadas na agricultura brasileira em termos de rendimento mensal familiar per capita. O rendimento médio na região sul do país teria crescido neste período. Porém, os autores afirmam que, como se trata do rendimento familiar per capita, ele inclui os rendimentos de membros ativos da família tanto em atividades agrícolas como não agrícolas. Portanto, a evolução favorável nos rendimentos médios poderia ser explicada em parte pelas oportunidades de trabalho 
que surgem para os moradores de áreas rurais nos outros setores da economia que não o agropecuário.

Schneider e Waquil (2001) afirmam que são apenas parcialmente verdadeiras as afirmações de que a pobreza da população rural do Rio Grande do Sul esteja associada à disponibilidade de fatores de produção. Eles citam como exemplo as regiões da Encosta Inferior e Superior do Nordeste, onde se encontram os estabelecimentos rurais pequenos, com sérias restrições na capacidade de uso dos solos, mas em que os indicadores de renda estão entre os mais elevados.

Schneider e Radomsky (2002) verificaram que há uma redução maior no número de pessoas ativas na agropecuária do que na população rural gaúcha. É que muitas pessoas continuam residindo no meio rural, mas assumindo cada vez mais atividades nos setores não agrícolas da economia. Os autores acreditam, com base em vários indicadores sobre a evolução do setor agropecuário gaúcho, que a tendência de os residentes rurais no Rio Grande do Sul assumirem empregos não agrícolas, em busca de maiores rendimentos, apesar de muitos continuarem residindo no meio rural, se intensificará nos próximos anos.

Portanto, os vários estudos mostram que os rendimentos do trabalho auferidos pelo trabalhador no meio rural são menores do que os recebidos no meio urbano.

Em relação à escolaridade do trabalhador, diversos autores descrevem os seus efeitos positivos sobre os rendimentos do trabalho.

Figueiredo Neto (1998) estimou equações de rendimentos, a partir de dados da PNAD (1995), para homens e mulheres residentes no meio urbano. Os retornos à escolaridade apresentaram valores positivos. Ele constatou, também, que os trabalhadores pertencentes aos setores secundário e terciário têm rendimentos mais elevados do que os integrantes do setor primário.

Arbache (2001) afirma que a liberalização comercial, ocorrida no Brasil desde o final da década de 1980 e durante a de 1990, teria provocado um aumento nas desigualdades de salários no mercado de trabalho, o que contraria a teoria tradicional do comércio internacional. A demanda por mão de obra qualificada teria crescido, como resultado de mudanças tecnológicas, fazendo aumentar a sua remuneração e elevando as desigualdades dos rendimentos do trabalho. 
Green, Felsted e Gallie (apud Arbache, 2001, p.10) observaram um incremento substancial nos rendimentos dos trabalhadores com curso superior, após a liberalização comercial, no Brasil.

Nahas et al. (2003), ao examinar dados referentes à região intraurbana de Belo Horizonte, constataram que havia correlações muito baixas da escolarização do $1^{\circ}$ grau com emprego e renda, mas altas correlações destas variáveis com a escolarização quando se trata do 2 e e 3 ograus.

Rocha (2001), com base em um estudo referente a seis regiões metropolitanas do país, para o período 1994 a 2000, concluiu que o mercado estava exigindo trabalhadores com maior qualificação. Segundo a autora, teria havido uma redução de 1,2 milhões de postos de trabalho ocupados por trabalhadores com até 4 anos de escolaridade entre abril de 1994 e abril de 1999. No mesmo período teria permanecido estável o número de postos de trabalho para pessoas com 4 a 8 anos de escolaridade e aumentado o número dos destinados a pessoas com mais de 8 anos de estudo. O rendimento médio dos trabalhadores com 12 anos ou mais de escolaridade seria 4,5 vezes superior ao daqueles com até 4 anos de estudo. Como resultado, o rendimento total para os trabalhadores com 12 anos de escolaridade ou mais apresentaria os maiores ganhos acumulados no período 1994/2000, enquanto declina sem cessar o rendimento daqueles com menos de 4 anos de escolaridade.

Kassouf (1997), com base em dados da Pesquisa Nacional sobre Saúde e Nutrição, coletados pelo IBGE em 1989, para todo o Brasil, concluiu que os retornos do trabalhador brasileiro à escolaridade e ao treinamento são maiores no setor urbano do que no rural. Os trabalhadores urbanos atingem o pico de rendimento mais cedo do que os do setor rural. Os trabalhadores do setor rural com bom treinamento seriam motivados a migrar para as cidades onde o retorno à sua qualificação seria maior.

Portanto, os diversos autores concordam que os rendimentos do trabalho no meio rural (setor agropecuário) são inferiores aos do meio urbano e que há um efeito positivo da escolaridade sobre estes rendimentos. 


\section{Metodologia}

\section{1 - Fonte dos dados}

A fonte dos dados é o Censo Demográfico de 2000 realizado pelo Instituto Brasileiro de Geografia e Estatística (IBGE). O censo informa o número de pessoas de 10 anos ou mais de idade, ocupadas na semana de referência, por classes de rendimento nominal mensal, em termos de salário mínimo, para cada um dos municípios do Rio Grande do Sul. Esta informação consta na tabela 2.7.7 do CD referente aos dados do Censo Demográfico.

Outra informação utilizada no estudo é o número de pessoas de 10 anos ou mais de idade, ocupadas na semana de referência, por seção de atividade do trabalho principal (tabela 2.7.6 do Censo Demográfico).

Os dados referentes à classificação das pessoas de 10 anos ou mais de idade por grupos de anos de estudo estão na tabela 2.2.2 do Censo Demográfico.

\section{2 - Análise estatística}

A análise estatística dos dados é feita através do modelo Logit (Gujarati, 2000, cap.16; Verbeek, 2000, cap.7).

As unidades de observação são os 467 municípios do Rio Grande do Sul incluídos no Censo Demográfico de 2000. Referente a cada município tem-se o percentual $P$ de pessoas que têm um rendimento mensal acima de um determinado valor. Este percentual P representa a probabilidade ou chance de uma pessoa do município, com mais de 10 anos de idade, ocupada na semana de referência, escolhida ao acaso, ter um rendimento acima deste patamar.

Assim, por exemplo, se o nível de rendimento considerado for um salário mínimo, o P representa o percentual das pessoas do município, dentre as que têm mais de 10 anos de idade e estavam ocupadas na semana de referência, que recebem como rendimento do trabalho mais que um salário mínimo. 
Em relação a cada município calcula-se o valor da variável

$$
L=\mathrm{h}\left(\frac{P}{1-P}\right) \text {. }
$$

Como variáveis explicativas, ou seja, que possam influir na probabilidade de uma pessoa ter um rendimento acima de certo patamar, considera-se a participação das pessoas ocupadas no município nos diversos setores de atividade e nos diversos níveis de escolaridade. Estas são as variáveis explicativas $X_{\mathrm{j}}$, com $\mathrm{j}=1, \ldots \mathrm{n}$.

A análise é realizada considerando-se, sucessivamente, diversos níveis mínimos de rendimento. O Censo Demográfico apresenta informações em relação aos seguintes níveis de rendimento, medidos em número de salários mínimos (SM): sem rendimento e até $1 \mathrm{SM}$; mais de 1 e até $2 \mathrm{SM}$; mais de 2 e até $3 \mathrm{SM}$; mais de 3 e até $5 \mathrm{SM}$; mais de 5 e até $10 \mathrm{SM}$; mais de 10 e até $20 \mathrm{SM}$; mais de 20 SM. Assim, os níveis de rendimento considerados neste estudo são os de um, dois, três, cinco e dez salários mínimos. Desconsidera-se o nível de mais de 20 salários mínimos pelo pequeno percentual de pessoas em cada município que ganham estes rendimentos do trabalho.

Para cada nível de rendimento calculam-se os valores $\mathrm{P}$ referentes aos 467 municípios e estima-se uma função do tipo:

$$
L=\beta_{0}+\sum_{j=1}^{n} \beta_{j} X_{j}+u_{i}
$$

Gujarati ( 2000, p.562) afirma que o termo de perturbação $u_{i}$ neste modelo é heteroscedástico. Procede-se, assim, ao teste de White (Patterson, 2000, p.161) para verificar se os resíduos $\mathrm{u}_{\mathrm{i}}$ são heteroscedásticos. Constatada a heteroscedasticidade nos resíduos, estima-se uma nova função pelo método de White para a correção deste problema.

Procede-se, também, ao teste da existência ou não de autocorrelação entre os resíduos $u_{i}$ da função (1) acima. O teste utilizado é o LM (multiplicador de Lagrange) de Breusch-Godfrey (Patterson, 2000, p.173). No caso da existência de heteroscedasticidade e autocorrelação entre os resíduos estima-se uma nova função pelo método de NeweyWest (Patterson, 2000, p.178) para a obtenção de covariâncias consistentes quanto à autocorrelação e heteroscedasticidade. 
Em relação à função (1), Gujarati (2000, p.565) afirma que: "Em geral, se você pegar o antilog do j-ésimo coeficiente de inclinação, dele subtrair 1 e multiplicar o resultado por 100 , você terá a variação percentual na chance devida ao aumento de uma unidade no j-ésimo regressor".

Pode-se, assim, avaliar como o aumento em um ponto percentual na participação dos trabalhadores em determinado setor de atividade ou nível de escolaridade aumenta a sua chance de serem incluídos no nível de rendimentos considerado na função.

As variáveis explicativas, com os respectivos símbolos, consideradas nas estimativas das funções, são como segue:

a) Participação percentual das pessoas ocupadas, com 10 anos ou mais de idade, em cada um dos setores de atividade abaixo (fonte: tabela 2.7.6 do Censo).

a.1) Agricultura, pecuária, silvicultura, exploração florestal e pesca. (agrope);

a.2) Indústria extrativa, indústria de transformação e distribuição de eletricidade, gás e água. (indus);

a.3) Construção (const);

a.4) Comércio, reparação de veículos automotores, objetos pessoais e domésticos (comer);

a.5) Transporte, armazenagem e comunicação (transp);

a.6) Intermediação financeira e atividades imobiliárias, aluguéis e serviços prestados às empresas (financ);

a.7) Administração pública, defesa e seguridade social (public).

b) Percentual das pessoas do município com 10 anos ou mais de idade por grupos de anos de estudo. (Fonte: tabela 2.2.2 do Censo).

b.1) com 1 a 3 anos de estudo (in1a3);

b.2) com 4 a 7 anos de estudo(in4a7);

b.3) com 8 a 10 anos de estudo (in8a10);

b.4) com 11 a 14 anos de estudo (i11a14);

b.5) com 15 ou mais anos de estudo (in $15 \mathrm{~m}$ ). 


\section{Resultados}

Os testes estatísticos e as estimativas das funções de regressão foram realizados através do software estatístico e econométrico denominado EViews 4.1.

Verificou-se, inicialmente, a existência ou não de heteroscedasticidade e autocorrelação entre os resíduos $u_{i}$ da função (1) acima. A hipótese nula de inexistência de heteroscedasticidade nos resíduos foi rejeitada, ao nível de significância de $1 \%$, nas regressões referentes aos níveis salariais de mais de um, de dois, de três e de cinco salários mínimos. Ela não foi rejeitada na regressão referente ao nível salarial maior do que dez salários mínimos. A hipótese nula de inexistência de autocorrelação entre os resíduos não foi rejeitada em nenhuma das cinco regressões, ao nível de significância estatística de $5 \%$.

Considerando os resultados dos testes, as funções referentes aos níveis salariais de mais de um, de dois, de três e de cinco salários mínimos foram re-estimadas pelo método de White para a correção do problema da heteroscedasticidade. Os resultados das regressões estatísticas estão na Tabela 1.

O setor da agricultura, pecuária, silvicultura, exploração florestal e pesca (agrope) não é estatisticamente significante em relação aos cinco níveis de rendimento. Isto significa que se aumentar a participação percentual deste setor no total das pessoas com 10 anos ou mais de idade, ocupadas em um determinado município, a probabilidade ou chance de uma pessoa auferir um rendimento maior do que qualquer um destes cinco níveis não aumenta.

Ocupando mais pessoas do município no setor agrícola, não irá aumentar as chances destas pessoas de auferirem maiores níveis de renda. É claro que este setor agrícola só inclui a produção primária. A transformação do produto primário é feita através da indústria. Esta sim tem um impacto positivo sobre a probabilidade das pessoas de um município obterem maiores rendimentos.

Os setores da indústria extrativa, indústria de transformação e distribuição de eletricidade, gás e água. (indus); da construção (const); da intermediação financeira e atividades imobiliárias, aluguéis e serviços prestados às empresas (financ); e o setor da administração pública, 
defesa e seguridade social (public) se mostraram estatisticamente significantes aos níveis de mais de um, de dois e de três salários mínimos.

Portanto, o crescimento da participação destes quatro setores na economia de um município contribuiria para o aumento da probabilidade de as pessoas auferirem mais de um, de dois e de três salários mínimos, não influenciando, porém, a chance de obtenção de rendimentos maiores que cinco salários mínimos.

O setor do comércio, reparação de veículos automotores, objetos pessoais e domésticos (comer) se mostrou estatisticamente significante em relação ao nível de um salário mínimo, mas não em relação aos demais níveis de rendimento.

O setor do transporte, armazenagem e comunicação (transp) influencia as probabilidades de as pessoas obterem rendimentos maiores que os cinco níveis considerados. Quanto mais importante este setor, em um determinado município, maiores são as chances de uma pessoa ocupada neste município obter um rendimento mais alto.

Uma maior participação dos trabalhadores do município no nível de escolaridade inferior a três anos de estudo não influencia a sua probabilidade de obtenção de maiores rendimentos. Já uma maior participação das pessoas com 4 a 7 anos de estudo aumenta as suas chances de rendimentos de até acima de cinco salários mínimos. Contudo, na regressão referente a mais de cinco salários mínimos, o coeficiente da variável relacionada ao nível de 4 a 7 anos de estudo é estatisticamente significante somente a $10 \%$.

O aumento na participação dos trabalhadores com uma escolaridade que vai de 8 a 10 anos de estudo eleva a sua chance de auferirem um rendimento maior do que um ou dois ou três salários mínimos. Porém, ao nível de mais de três salários mínimos o coeficiente só é estatisticamente significante a $10 \%$. 


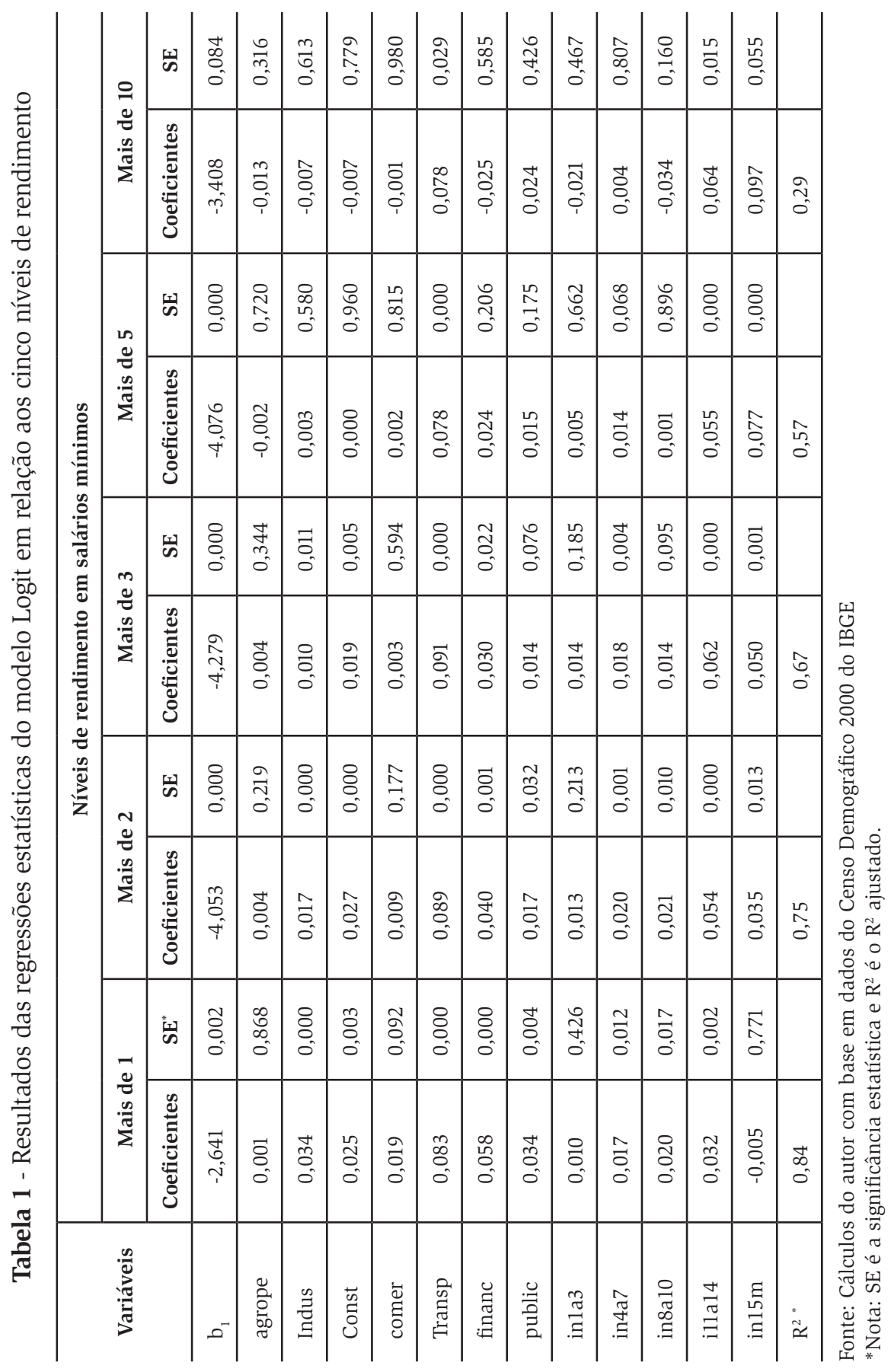


Uma maior participação dos trabalhadores do município no nível de escolaridade de 11 a 14 anos aumenta a sua probabilidade de um maior rendimento em relação a todos os níveis considerados. E um nível de estudos correspondente a 15 anos ou mais não influencia as chances de as pessoas auferirem mais do que um salário mínimo, mas sim, de obterem mais do que dois, três, cinco ou dez salários mínimos.

Com base na afirmação de Gujarati (2000, p.565) de que: "Em geral, se você pegar o antilog do j-ésimo coeficiente de inclinação, dele subtrair 1 e multiplicar o resultado por 100, você terá a variação percentual na chance devida ao aumento de uma unidade no j-ésimo regressor " se estima os aumentos percentuais nas probabilidades de os trabalhadores auferirem maiores rendimentos quando a participação das pessoas ocupadas em um setor ou em um grupo de anos de escolaridade aumentar em um ponto percentual. Como as variáveis $\mathrm{X}_{\mathrm{j}}$ são expressas em participações percentuais, a variação em uma unidade de cada variável significa um ponto percentual nesta participação.

A Tabela 2 apresenta estes resultados obtidos com base nos valores constantes na Tabela 1. No cálculo, foram desconsiderados os coeficientes que não são estatisticamente diferentes de zero ao nível de significância de $10 \%$, conforme a Tabela 1 .

A Tabela 2 permite uma visualização mais clara da importância das diversas variáveis sobre as probabilidades de um trabalhador auferir maiores rendimentos. Observa-se que o impacto maior ocorre com o aumento de um ponto percentual na participação do grupo das pessoas ocupadas com 15 anos ou mais de estudo em um município. Este acréscimo de um ponto percentual na participação deste grupo resulta em uma elevação de 10,19\% na probabilidade de as pessoas ocupadas neste município auferirem rendimentos acima de 10 salários mínimos. 
Tabela 2 - Aumentos percentuais nas probabilidades de um trabalhador auferir um rendimento acima do especificado quando

a participação das pessoas ocupadas na classe definida pela variável aumenta um ponto percentual

\begin{tabular}{l|c|c|c|c|c}
\hline \multirow{2}{*}{ Variáveis } & \multicolumn{5}{|c}{ Níveis de rendimento em salários mínimos } \\
\cline { 2 - 6 } & Mais de 1 & Mais de 2 & Mais de 3 & Mais de 5 & Mais de 10 \\
\hline Indus & 3,46 & 1,71 & 1,01 & & \\
\hline Const & 2,53 & 2,74 & 1,92 & & \\
\hline Comer & 1,92 & & & & \\
\hline Transp & 8,65 & 9,31 & 9,53 & 8,11 & 8,11 \\
\hline Finance & 5,97 & 4,08 & 3,05 & & \\
\hline Public & 3,46 & 1,71 & 1,41 & & \\
\hline In4a7 & 1,71 & 2,02 & 1,82 & 1,41 & \\
\hline in8a10 & 2,02 & 2,12 & 1,41 & & \\
\hline I11a14 & 3,25 & 5,55 & 6,40 & 5,65 & 6,61 \\
\hline In15m & & 3,56 & 5,13 & 8,00 & 10,19 \\
\hline
\end{tabular}

Fonte: Cálculos do autor com base em dados do Censo Demográfico 2000 do IBGE

A segunda variável que causa um grande impacto sobre a probabilidade de as pessoas auferirem um maior rendimento é a sua participação no setor do transporte, armazenagem, comunicação (transp). O impacto deste setor se estende em relação aos cinco níveis de rendimento.

\section{Conclusões}

Os resultados do estudo indicam que o aumento na participação das pessoas ocupadas no setor agrícola de um município não eleva as suas chances de auferirem maiores rendimentos do trabalho. Este resultado confere com as conclusões dos autores referidos acima, os quais afirmam que estes rendimentos no meio rural são inferiores aos do meio urbano.

O rural, para manter a população ocupada no seu meio, reduzindo os incentivos para a migração rural-urbana, não pode permanecer apenas na produção primária do produto agrícola, já que isto não aumentaria as chances de maiores salários para os trabalhadores envolvidos. Maior rendimento é o maior incentivo para manter o trabalhador no meio rural. 
O setor do transporte, armazenagem e da comunicação é importante para elevar a probabilidade de as pessoas ocupadas obterem salários maiores que qualquer um dos cinco níveis considerados. $\mathrm{O}$ setor industrial também contribui para elevar as chances de obtenção de rendimentos de mais de um, de dois e de três salários mínimos. Assim, o município deve, na medida do possível, incorporar ao meio rural as fases subseqüentes do processo produtivo agrícola, como a agroindústria, a armazenagem e o transporte, pelo menos até os primeiros pontos de destino, do produto agrícola, para assim aumentar as chances das pessoas ocupadas neste meio auferirem maiores rendimentos, desestimulando-as da migração rural-urbana.

O setor da construção civil; o setor da intermediação financeira e atividades imobiliárias, aluguéis e serviços prestados às empresas; e o setor da administração pública, defesa e seguridade social; contribuem para aumentar as chances de obtenção de rendimentos do trabalho maiores que um ou dois ou três salários mínimos. Dentre estes três setores o da construção civil merece destaque, pois além de gerar renda diretamente, também o faz via atividades imobiliárias e aluguéis, além de resultar em moradias para a população. Portanto, este setor merece ser incentivado pelos governos.

Os setores da construção civil, do transporte e armazenagem internos, por não competirem no mercado internacional, poderiam ter sido influenciados favoravelmente, em relação a outros setores, com a abertura comercial.

O setor que corresponde ao comércio, reparação de veículos automotores, objetos pessoais e domésticos contribui para aumentar as chances das pessoas obterem mais de um salário mínimo, não influenciando as chances de obtenção de rendimentos mais elevados.

Os resultados mostram a importância dos anos de escolaridade das pessoas para elevar as suas chances de obtenção de maiores salários. Os maiores aumentos na probabilidade de os trabalhadores obterem salários mais elevados ocorrem quando aumenta a sua participação nos níveis de escolaridade de 11 a 14 anos (segundo grau completo) e no nível de mais de 15 anos (curso superior). Este resultado confirma as conclusões de Nahas et al (2003) e Rocha (2001). Daí a importância de o poder público possibilitar o acesso a escolas de segundo grau para a 
população em cada um dos diversos municípios do estado. Como estas escolas estão geralmente localizadas na sede do município, a locomoção até as mesmas, pelos alunos do meio rural, deve ser facilitada.

O maior aumento na probabilidade de obtenção de rendimentos mais elevados ocorre em relação ao nível de mais de dez salários mínimos. Isto acontece quando cresce a participação, entre as pessoas ocupadas, daquelas com curso superior (15 anos ou mais de escolaridade). Este resultado está de acordo com as conclusões de Green, Felsted e Gallie (apud Arbache, 2001, p.10) de que haveria um aumento substancial nos rendimentos dos trabalhadores com curso superior. Deve-se ressaltar, porém, que o $\mathrm{R}^{2}$ ajustado da regressão referente a mais de 10 salários mínimos é igual a somente 0,29 (vide Tabela 1). Isto significa que o conjunto de variáveis desta regressão explica pouco da variação na probabilidade de maiores níveis de renda.

A conclusão geral do estudo é que são limitadas as possibilidades de obtenção de maiores rendimentos do trabalho no setor agrícola enquanto o mesmo for apenas gerador do produto primário. Os rendimentos do trabalho no meio rural poderiam ser aumentados com a incorporação ao mesmo de setores da atividade econômica relacionados com a produção agrícola, como por exemplo, a agroindústria, a armazenagem e o transporte de insumos e produtos agrícolas, contribuindo para a redução da migração rural-urbana.

Ao nível do município os setores que parecem contribuir para elevar os rendimentos das classes de renda mais baixas (que ganham até um pouco mais que três salários mínimos) são os da indústria, distribuição de eletricidade, gás e água; o da construção; o setor do transporte, armazenagem e comunicação; o setor da intermediação financeira e atividades imobiliárias, aluguéis e serviços prestados às empresas; e o setor da administração pública, defesa e seguridade social. Portanto, a estes deve ser dada a ênfase em políticas de desenvolvimento do município, acompanhadas da qualificação dos trabalhadores para assumir funções, até então desconhecidas pelos mesmos, nos novos setores.

Com exceção do setor do transporte, armazenagem e comunicação, os demais setores analisados parecem não contribuir para elevar a probabilidade de os trabalhadores receberem rendimentos mais elevados, ou seja, acima de cinco ou dez salários mínimos. Talvez este 
fato se deva a que, nos muitos municípios pequenos do estado, a participação, em cada setor, dos trabalhadores que recebam níveis salariais altos seja reduzida.

\section{Referências bibliográficas}

ARBACHE, J. S. trade liberalization and labor markets in developing countries: theory and evidence. Texto para Discussão № 853 - IPEA Rio de Janeiro 2001.

BACHA, E. L. crescimento econômico, salários urbanos e rurais: o caso do Brasil. Pesquisa e Planejamento Econômico. v. 9, № 3, p.585-628, dez. 1979.

CORRÊA, A. M. C. J.; CRÓCOMO, F. C.; MONTEBELO, M. I. de L.; FIGUEIREDO, N. S. de. "Bem estar, pobreza e desigualdade de rendimentos entre as pessoas ocupadas na agricultura brasileira: uma avaliação da evolução e das disparidades regionais no período 1995-1999”. XL Congresso Brasileiro de Economia e Sociologia Rural. SOBER Passo Fundo -RS. 28 a 31 de julho de 2002 .

FIGUEIREDO NETO, L. F. Determinantes da participação no mercado de trabalho e dos rendimentos e retornos aos investimentos em capital humano. Análise Econômica. Ano 16 №29 - Porto Alegre - 1998

GUJARATI, Damodar N. Econometria Básica. $3^{a}$ edição. Makron Books do Brasil Editora Ltda. São Paulo. 2000.

IBGE - Censo demográfico. Rio de Janeiro. 2000.

JOHNSTON, B. F. \& MELLOR, J.W. The Role of Agriculture in Economic Development, American Economic Review, Vol. 51, p.566-93. 1961.

KASSOUF, A. L. Retornos à escolaridade e ao treinamento nos setores urbano e rural do Brasil. Revista de Economia e Sociologia Rural. SOBER. № 2. Brasília 1997.

NAHAS, M. I. P.; OLIVEIRA, A. M. de; CARVALHO NETO, A. Acesso à ocupação e à rend $a$ versus escolarização no espaço intra-urbano de grandes cidades: o caso de Belo Horizonte. X Seminário sobre a Economia Mineira. CEDEPLAR-UFMG 2002 Site: http://www.cedeplar.ufmg.br (acessado em 06/11/2003).

PATTERSON, K. An introduction to applied econometrics: a time series approach. St. Martin’s Press. Nova Iorque. 2000.

ROCHA, S. Pobreza no Brasil O que há de novo no limiar do século XXI? Economia. ANPEC. V. 2, n. 1 p.73-106. Rio de Janeiro. 2001. 
SCHNEIDER, S.; WAQUIL, P. D. Caracterização socioeconômica dos municípios gaúchos e desigualdades regionais. Revista de Economia e Sociologia Rural. SOBER. V.39 № 3. Brasília. 2001.

SCHNEIDER, S.; RADOMSKY, G. W. Agricultura e emprego rural na década de 1990 no Rio Grande do Sul. XL Congresso Brasileiro de Economia e Sociologia Rural. SOBER. Passo Fundo -RS. 28 a 31 de Julho de 2002.

SOUZA, N. de J. de. Desenvolvimento Econômico. 2a edição. Editora Atlas S.A. São Paulo. 1995.

VERBEEK, Marno. A guide to modern econometrics. John Wiley \& Sons, Ltd. West Sussex. Inglaterra. 2000.

WAQUIL, P. D.; MATTOS, E. J. de. Distribuição de renda no Rio Grande do Sul: um comparativo entre o rural e o urbano. 1 Encontro de Economia Gaúcha. PUCRS. 16 e 17 de maio de 2002.

Recebido em novembro de 2004 e revisto em março de 2006 